Laser Chem., 1999, Vol. 19, pp. 245-251

Reprints available directly from the publisher Photocopying permitted by license only
(C) 1999 OPA (Overseas Publishers Association) N.V. Published by license under the Harwood Academic Publishers imprint, part of The Gordon and Breach Publishing Group.

\title{
EXCITED STATES AND INTERMEDIATES BY TIME-RESOLVED INFRARED SPECTROSCOPY
}

\author{
J. J. TURNER, M. W. GEORGE*, I. P. CLARK \\ and I. G. VIRRELS \\ School of Chemistry, University of Nottingham, \\ Nottingham NG7 2RD, UK
}

(Received 20 April 1997)

For coordination compounds containing $\mathrm{CO}$ or $\mathrm{CN}$ groups, fast time-resolved infrared spectroscopy (TRIR) provides a convenient method of probing excited states and intermediates. TRIR has proved particularly powerful for probing the structure and kinetics of organometallic intermediates. The interpretation is particularly straightforward when combined with IR data from matrix isolation experiments, although there can be some subtle differences. In excited state studies, shifts in $\nu(\mathrm{CO})$ and $\nu(\mathrm{CN})$ frequencies, from ground to excited state, are sensitive to the changes in electron distribution on excitation, thus allowing the distinction between charge-transfer and non-charge-transfer transitions. Subtle effects on excited state $\nu(\mathrm{CO})$ band positions occur with change from fluid to rigid solvent - "infrared rigidochromism". There is often a change in $\nu(\mathrm{CO})$ band width on excitation; this can be interpreted in terms of specific interactions between the excited species and the solvent. This paper presents some of our recent work in this area.

Keywords: Excited states; intermediates; time-resolved infrared spectroscopy

\section{STUDIES ON ORGANOMETALLIC INTERMEDIATES}

The study of intermediates in organometallic photochemistry has been greatly helped by the use of the matrix isolation technique [1], using either frozen noble gases at $\sim 10 \mathrm{~K}$ or hydrocarbon glasses at $\sim 77 \mathrm{~K}$.

\footnotetext{
* Corresponding author. Tel.: 0115 9513559; Fax: 01159513563.
} 
Infrared spectroscopy has been the most powerful technique for investigating the trapped species, because the $\nu(\mathrm{CO})$ bands of $\mathrm{CO}-$ containing organometallics are very intense and usually narrow, and provide detailed structural information. In contrast, UV/vis bands are usually broad and featureless and hence contain little structural information. Similarly there are advantages in probing intermediates at room temperature by fast IR spectroscopy [2]. As an example where the two techniques provide complementary information, we describe recent results on the photochemistry of $\left[\mathrm{Cp}^{*} \mathrm{Cr}(\mathrm{CO})_{2}\right]_{2}\left(\mathrm{Cp}^{*}=\right.$ $\left.\eta^{5}-\mathrm{C}_{5} \mathrm{Me}_{5}\right)$ 1. The compound has the structure: [3]

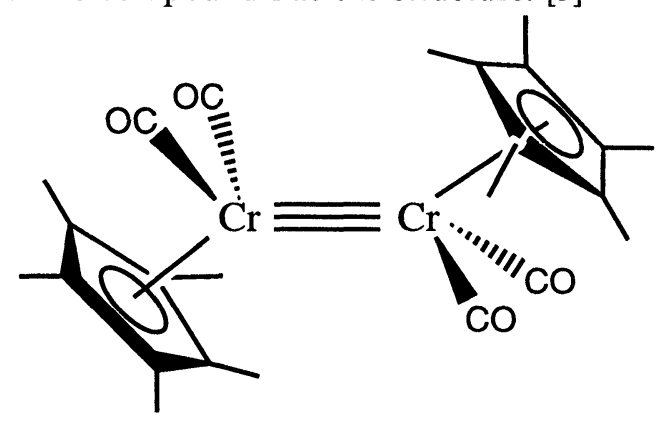

Photolysis in the presence of ${ }^{13} \mathrm{CO}$ (or $\mathrm{PF}_{3}$ ) leads to $\mathrm{Cp}^{*} \mathrm{Cr}(\mathrm{CO})\left({ }^{13-}\right.$ $\mathrm{CO}) \mathrm{Cr}(\mathrm{CO})_{2} \mathrm{Cp}^{*}$ (or $\mathrm{Cp}^{*} \mathrm{Cr}(\mathrm{CO})\left(\mathrm{PF}_{3}\right) \mathrm{Cr}(\mathrm{CO})_{2} \mathrm{Cp}^{*}$ ); probably for steric reasons there is no reaction with, e.g., $\mathrm{PPh}_{3}$ [4]. Photolysis of 1 in a low temperature matrix [5] shows loss of the terminal $\nu(\mathrm{CO})$ bands and production of a single band in the bridging $\mathrm{CO}$ region, consistent with the formation of a triply bridged species $\mathrm{Cp}^{*} \mathrm{Cr}(\mu-\mathrm{CO})_{3} \mathrm{CrCp}^{*}$, with the $\mathrm{CO}$ groups possessing local $\mathrm{D}_{3 h}$ symmetry, hence leading to only one active $\nu(\mathrm{CO})$ band, the $e$ mode. Figure 1 shows what happens in a room temperature TRIR experiment; it is clear that there is loss of terminal $\nu(\mathrm{CO})$ bands assigned to parent and generation of an intermediate with two bands in the $\nu(\mathrm{CO})$ bridging region. Detailed experiments show that these bands belong to the same species and in fact arise because the local geometry of the $\mathrm{CO}$ groups is not actually $\mathrm{D}_{3 h}$, but more likely $\mathrm{C}_{S}$. In the matrix the $\nu(\mathrm{CO})$ band is too broad to detect the lowering of symmetry. The reasons for the distortion are discussed elsewhere [6]. 


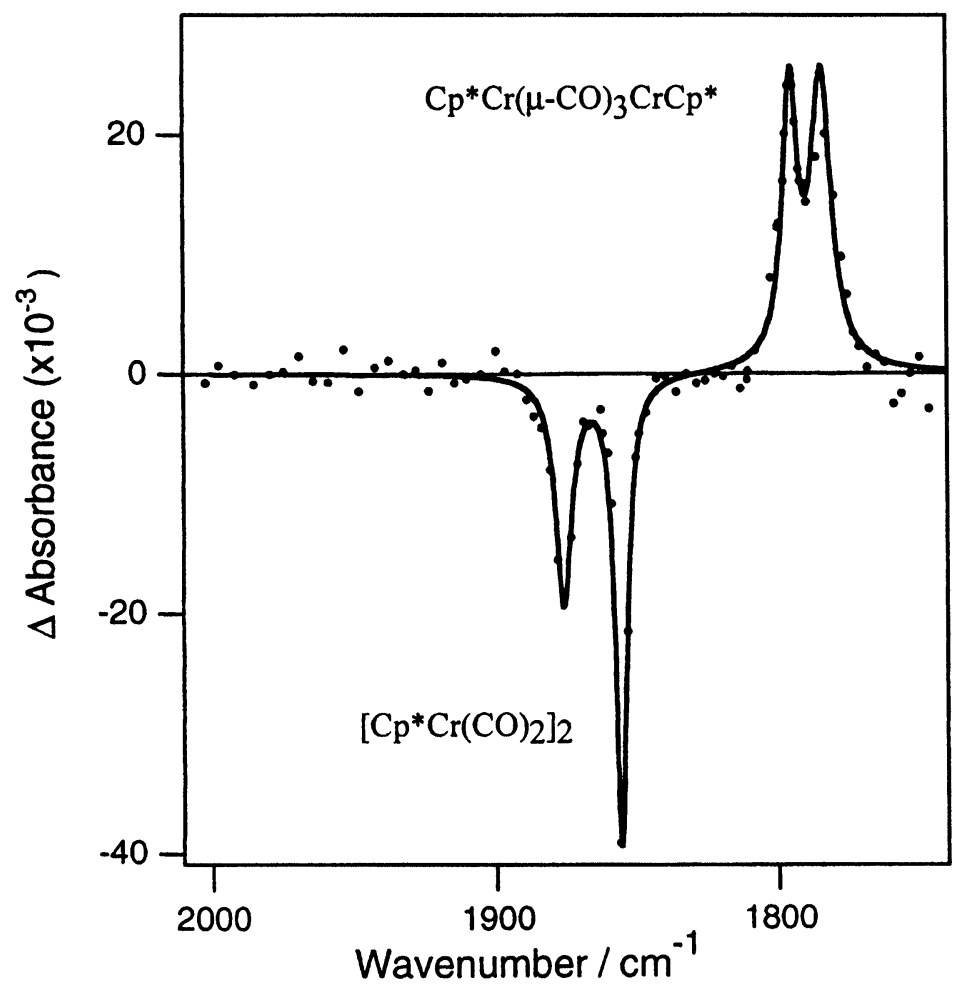

FIGURE 1 TRIR spectrum, obtained $200 \mathrm{~ns}$ after flash photololysis $(355 \mathrm{~nm})$, of [Cp* $\left.\mathrm{Cr}(\mathrm{CO})_{2}\right]_{2}$ in $n$-heptane $\left(5 \times 10^{-4} \mathrm{M}\right)$. Data points plotted downwards indicate loss of parent; data points plotted upwards indicate generation of the new species, $\left[\mathrm{Cp}^{*} \mathrm{Cr}(\mu-\mathrm{CO})_{3} \mathrm{CrCp}^{*}\right]$.

\section{STUDIES ON THE EXCITED STATES OF COORDINATION COMPOUNDS}

The first coordination compound whose excited state IR spectrum was obtained was $\mathrm{ClRe}(\mathrm{CO})_{3}\left(4,4^{\prime} \text {-bipyridine }\right)_{2}$ [7]. In the excited state there is charge transfer from Re to bipy ligand, resulting in a lowering of electron density on the Re and thus less back-bonding to the CO groups, with the consequent rise in $\nu(\mathrm{CO})$ frequencies. Since then there has been considerable application of TRIR to excited states [8]. The molecule $\operatorname{ClRe}(\mathrm{CO})_{3}\left(2,2^{\prime}\right.$-bipyridine $) 2$ has proved to be useful 
"testbed" for observations on novel features in excited state IR spectra [9]. These include infrared rigidochromism and $\nu(\mathrm{CO})$ bandwidths.

\section{(a) Infrared Rigidochromism}

The phenomenon of "luminescence rigidochromism" is well known [10]. When molecules exhibiting charge transfer excited states are trapped in rigid matrices the emission from the CT excited state undergoes a shift to the blue. We have investigated the effect on the IR absorption spectrum, in ground and MLCT excited state, of 2, on freezing in a glass of $\operatorname{PrCN} / \operatorname{EtCN}$ (5:4 v:v) [11]. There is only a small shift in the ground state $\nu(\mathrm{CO})$ frequencies; however the shift from ground to excited state is much less in the glass than in room temperature solution. It is important to establish that this is an effect of the change in rigidity of the environment and not an effect of the lowering of the temperature. Figure 2 shows a plot of two parameters: the lifetime of the excited state, and the mean shift to high frequency of

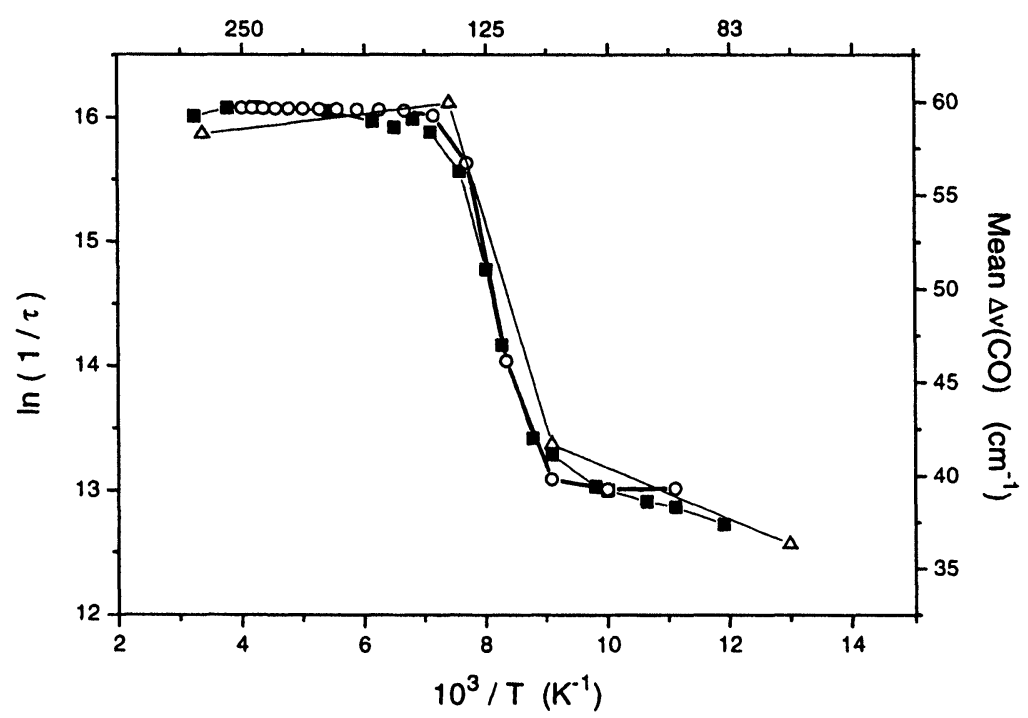

FIGURE 2 Plot $(\square)$ of $\ln (1 / \tau)(\tau=$ lifetime $) v s . T^{-1}(T=$ temperature $)$ for the excited state of 2 in $\operatorname{PrCN} / \operatorname{EtCN}(5: 4$, v:v.). The four points $(\Delta)$ are the values of the mean shift in $\nu(\mathrm{CO})$ from ground to excited state. Also shown is a theoretical plot $(\mathrm{O})$ based on an equation from Ref. [12]. 
the three $\nu(\mathrm{CO})$ bands of 2 . Also shown is a theoretical plot based on equations from work by Balzani and colleagues [12]; full details will be published elsewhere [13]. The theoretical plot encompasses the rigid/ fluid transition and hence confirms the phenomenon of "infrared rigidochromism". The most likely interpretation in this case is that the increased rigidity raises the MLCT level and causes mixing with a non charge transfer state (perhaps $\pi \pi^{*}$ ), and hence there is less backbonding to the $\mathrm{CO}$ groups; however further experiments are required with a wide range of compounds.

\section{(b) $v(\mathrm{CO})$ Bandwidths}

It has been noted before that the widths of Raman bands of molecules in electronic excited states are often broader than the corresponding ground state bands [14]. It is noteable that this phenomenon seems also to apply to the infrared spectra of some coordination compounds in their excited states. Figure 3 shows such an example involving 2 . We have investigated this effect more fully by studying the behaviour of the $\nu(\mathrm{CO})$ bands of $\mathrm{W}(\mathrm{CO})_{5}$ (4-acetylpyridine), in both ground and MLCT excited state, and in both polar and non polar solvents. These experiments show that in a non-polar solvent, there is only a marginal difference in band width on excitation, whereas in a polar solvent, the band widths in the excited state are considerably increased. We attribute this to greater coupling between charge separated excited state and polar solvent. Further details can be found elsewhere [15].

\section{EXPERIMENTAL}

The Nottingham TRIR apparatus has been described in detail elsewhere [16]. Briefly, a pulsed Nd:YAG laser (Quanta-Ray GCR$11 ; 266 \mathrm{~nm}$ or $355 \mathrm{~nm}$ ), is used to initiate the photochemical reaction and a cw infrared source, (Mütek IR diode laser) monitors the changes in infrared transmission following the UV/visible pulse. IR spectra are built up on a "point-by-point" basis by repeating this measurement at different infrared frequencies. 


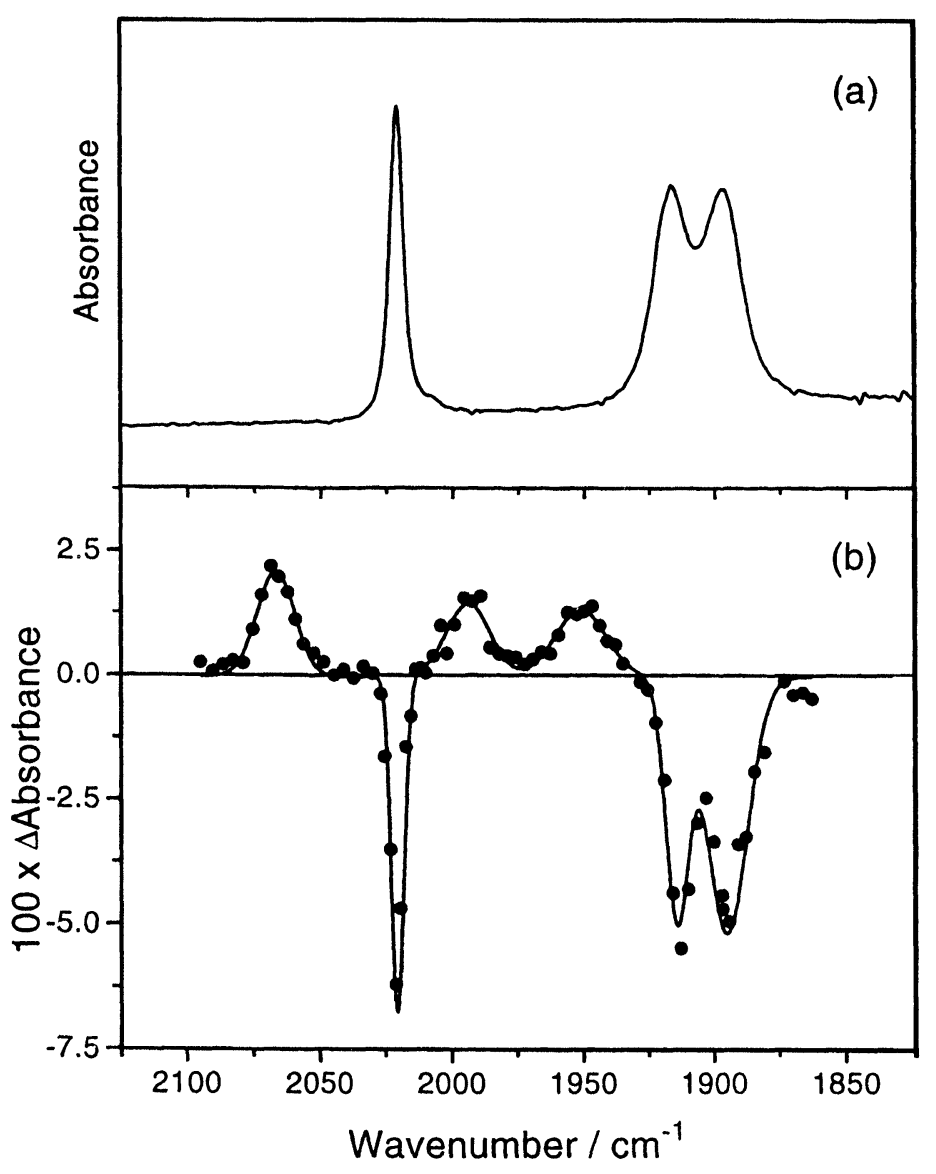

FIGURE 3 FTIR spectrum 2 of in PrCN;EtCN (5:4 v:v). (b) TRIR spectra of the same solution, recorded $100 \mathrm{~ns}$ after $355 \mathrm{~nm}$ photolysis.

\section{CONCLUSION}

It is clear that fast infrared spectroscopy can provide significant new information about the photochemical and photophysical behaviour of transition metal molecules containing $\mathrm{CO}$ groups. The position, intensity and shape of the $\nu(\mathrm{CO})$ bands provide clues about structure and dynamics. 


\section{Acknowledgements}

We acknowledge financial support from EPSRC, EU, Perkin-Elmer, Mütek and the University of Nottingham.

\section{References}

[1] Almond, M. J. (1990). "Short-lived Molecules", Ellis-Horwood, New York; Perutz, R. N. (1993). Chem. Soc. Rev., 22, 361.

[2] Poliakoff, M. and Weitz, E. (1986). Adv. Organomet. Chem., 25, 277; Grevels, F.W., Klotzbücher, W. E. and Schaffner, K., Chem. Rev., in press. Recent references include: Virrels, I. G., George, M. W., Turner, J. J., Peters, J. and Vlcek, A. (1996). Organometallics, 15, 4089; Virrels, I. G., George, M. W., Johnson, F. P. A., Turner, J. J. and Westwell, J. R. (1995). Organometallics, 14, 5203.

[3] Potenza, J., Giordano, P., Mastropaolo, D. and Efraty, A. (1974). Inorg. Chem., 13, 2540.

[4] Robbins, J. L. and Wrighton, M. S. (1981). Inorg. Chem., 20, 1133.

[5] Hooker, R. H. and Rest, A. J. (1990). J. Chem. Soc. Dalton Trans., p. 1221.

[6] Virrels, I. G., Nolan, T. F., George, M. W. and Turner, J. J., to be published.

[7] Glyn, P., George, M. W., Hodges, P. M. and Turner, J. J. (1989). J. Chem. Soc. Chem. Commun., 1655; Gamelin, D. R., George, M. W., Glyn, P., Grevels, F.-W., Johnson, F. P. A., Klotzbücher, W., Morrison, S. L., Russell, G., Schaffner, K. and Turner, J. J. (1994). Inorg. Chem., 33, 3246.

[8] Turner, J. J., George, M. W., Johnson, F. P. A. and Westwell, J. R. (1993). Coord. Chem. Rev., 125, 101; Bignozzi, C. A., Schoonover, J. R. and Dyer, R. B. (1996). Comments Inorg. Chem., 18, 77; Schoonover, J. R. (1998). Chem. Rev., 98, 1335.

[9] George, M. W., Johnson, F. P. A., Westwell, J. R., Hodges, P. M. and Turner, J. J. (1993). J. Chem. Soc. Dalton Trans., p. 2977.

[10] Wrighton, M. S. and Morse, D. L. (1974). J. Am. Chem. Soc., 96, 998.

[11] Clark, I. P., George, M. W. and Johnson, F. P. A. (1996). Chem. Commun., p. 1587.

[12] Barigelletti, F., Belser, P., von Zelewsky, A., Juris, A. and Balzani, V. (1985). J. Phys. Chem., 89, 5307.

[13] Clark, I. P., George, M. W. and Turner, J. J., to be published.

[14] Hamaguchi, H. and Gustafson, T. L. (1994). Annu. Rev. Phys. Chem., 45, 593.

[15] Johnson, F. P. A., George, M. W. and Turner, J. J. (1993). Inorg. Chem., 32, 4226; Clark, I. P., George, M. W. and Tuner, J. J., submitted for publication.

[16] George, M. W., Poliakoff, M. and Turner, J. J. (1994). The Analyst, 119, 551. 